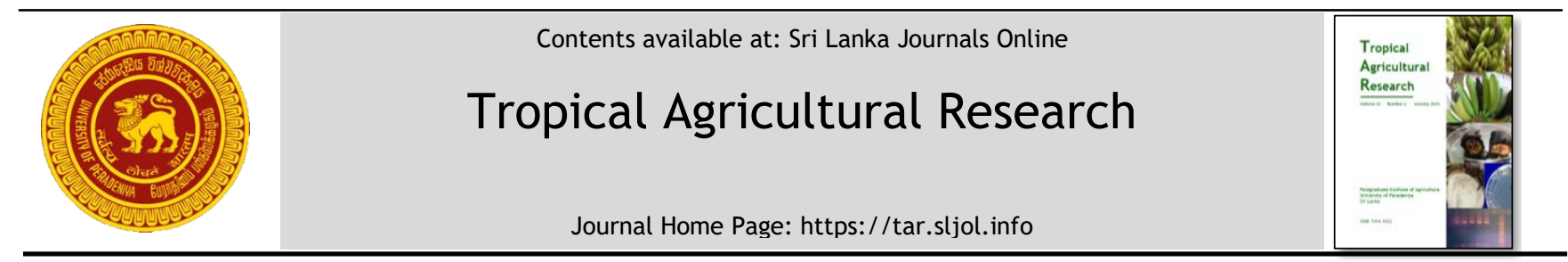

\title{
Response of Canopy Leaf Area Index and Architecture of Tropical Rainforests in Sri Lanka to Climatic Variation along an Altitudinal Gradient
}

\author{
R.M.C. Madhumali ${ }^{*}{ }^{*}$, W.M.P.S.B. Wahala ${ }^{1}$, H.K.N. Sanjeewani ${ }^{2}$, D.P. Samarasinghe ${ }^{3}$ and W.A.J.M. De Costa ${ }^{4}$ \\ ${ }^{1}$ Faculty of Graduate Studies, Sabaragamuwa University of Sri Lanka. \\ ${ }^{2}$ Postgraduate Institute of Agriculture, University of Peradeniya, Peradeniya, Sri Lanka. \\ ${ }^{3}$ Postgraduate Institute of Archaeology, University of Kelaniya, Kelaniya, Sri Lanka. \\ ${ }^{4}$ Department of Crop Science, Faculty of Agriculture, University of Peradeniya, Peradeniya, Sri Lanka
}

\section{ARTICLE INFO}

\section{Article history:}

Received: 15 July 2020

Revised version received: 11 October 2020

Accepted: 5 November 2020

Available online: 1 January 2021

\section{Keywords:}

Altitude

Leaf Angle

Leaf Area Index

Tropical rainforests

\section{ABSTRACT}

The foliage canopy of a forest is important for radiation capture, carbon sequestration and regulation of water relations. The objective of this work was to quantify the response of key canopy properties of tropical rainforests of Sri Lanka (TRFSL) to the variation in altitude and associated climatic variables. Canopy hemispherical photography was used to measure leaf area index (LAI), ellipsoidal leaf angle distribution parameter (ELADP) and mean leaf angle (MLA) in ten 1 ha permanent sampling plots (PSPs) established across an altitudinal gradient from $117 \mathrm{~m}$ to $2132 \mathrm{~m}$ above mean sea level. All three canopy properties varied significantly $(\mathrm{p}<0.1)$ among PSPs. Both LAI and MLA showed second-order polynomial responses to altitude, with maxima at $658 \mathrm{~m}$ and $773 \mathrm{~m}$, respectively. The ELADP showed an inverse second-order polynomial response to altitude, with a minimum at $716 \mathrm{~m}$. The long-term mean annual precipitation $\left(\mathrm{R}_{\mathrm{F}}\right)$ was the main determinant of LAI, showing a positive, linear relationship, confirming the influence of water availability in determining canopy size. Long-term solar irradiance $\left(S_{R}\right)$ was a key climatic factor determining canopy architecture, where the proportion of relatively horizontally oriented leaves increased (ELADP $>1$ ) and MLA decreased with decreasing $S_{R}$ from mid- to upper altitudes (>700 $\mathrm{m}$ amsl). This was an adaptation to maximize radiation interception. The LAI decreased from mid to lower altitudes ( $<700 \mathrm{~m}$ amsl) as an adaptation to reduce transpiration under higher $S_{R}$ and $T_{A V}$ in the lower altitudes, forcing canopy architecture towards horizontally-oriented leaves to maximize radiation interception. These responses could be influential in the overall response of TRFSL to climate change. 


\section{INTRODUCTION}

The canopy can be considered as the core of a forest as physiological processes of primary production take place in leaves. Vertical and horizontal structuring of the forest canopy is responsible for distribution of solar radiation within a forest (Fotis and Curtis, 2017) The canopy size and structure play major roles in important ecophysiological processes such as photosynthesis, evapotranspiration and net primary production (Perry et al., 1988; Welles and Norman, 1991; Pearcy, 2000). Quantitative assessments of canopy size and structure of forests provide information for estimation of biomass, carbon and nutrient fluxes, forest inventory, biodiversity conservation and assessment of impacts of environmental change (Chianucci and Cutini, 2012; Fournier and Hall, 2017).

The structure of a forest canopy can be described in terms of the effective area of its foliage elements and their arrangement in space (i.e. canopy architecture). Effective leaf surface area is measured as the leaf area index (LAI), which is defined for broadleaf vegetation as the one-sided leaf area per unit of ground area (Monteith and Unsworth, 1990). Leaf angle distribution of individual foliage elements allows quantification of forest canopy architecture in terms of radiation penetration, which determines photosynthetic and transpiration rates along with the leaf energy balance (Wang et al., 2007). The ellipsoidal model of leaf angle distribution assumes that leaves of a foliage canopy have a distribution of angles which cover the surface of an ellipsoid, which is symmetrical around its vertical axis (Campbell,
1986). The ellipsoidal leaf angle distribution parameter (ELADP) is defined as the ratio between the semi-horizontal and semi-vertical axes of the ellipsoid (Figure 1). Accordingly, a canopy with a higher proportion of relatively horizontallyoriented leaves has an ELADP > 1 whereas a higher proportion of vertically-oriented leaves would make ELADP $<1$. The Mean leaf angle (MLA), defined as the average inclination angle of an area of foliage to the horizontal (Campbell, 1990), provides a summary statistic to quantify canopy architecture.

Environmental variation with increasing altitude (Körner, 2007) could exert a significant influence on the canopy structure of a tropical rainforest. Tropical rainforests of Sri Lanka (TRFSL) exhibit substantial variation in tree density, tree basal area, floristic composition and above-ground standing biomass with altitude (Sanjeewani et al., 2020). Previous studies on TRFSL have described their canopy structure in terms of tree species occupying different canopy strata (Gunatilleke and Gunatilleke, 1984; Gunatilleke and Gunatilleke, 1985; Gunatilleke and Ashton, 1987). However, quantitative descriptions of canopy structure of TRFSL, in terms of canopy size and architecture are limited (Ediriweera et al., 2008). In view of the importance of TRFSL for biodiversity conservation and possible amelioration of adverse climatic effects, investigation of canopy size and structure, its variation and factors influencing this variation would fill an important knowledge gap. Therefore, the principal objectives of this work were, to quantify the variation of LAI, ELADP and MLA of TRFSL across a wide altitudinal gradient,

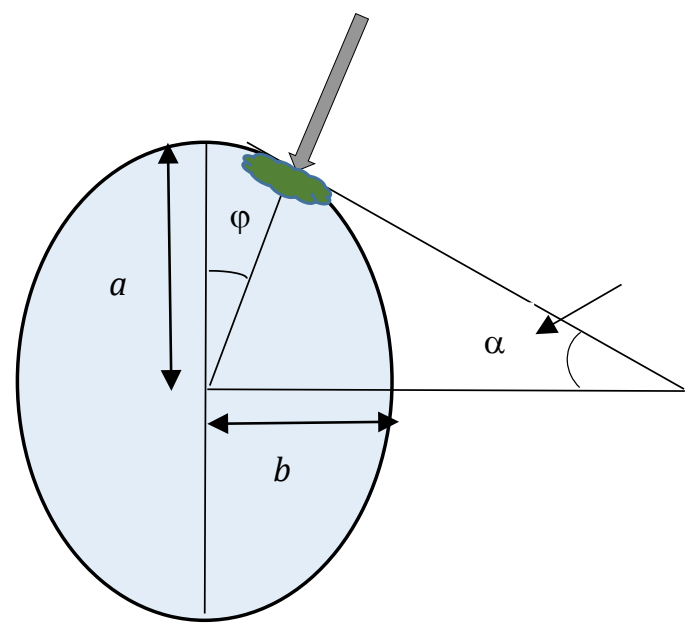

Figure 1: Features of the ellipsoidal model of leaf angle distribution of a foliage canopy. $\alpha$ - Leaf inclination angle; $\varphi$ - Zenith angle of incident radiation on the canopy (indicated by arrow). $a$ and $b$ are semi-vertical and semi-horizontal axes of the ellipsoid. ELADP is computed as $b / a$ (Adapted from Campbell, 1990). 
and to determine the influence of climatic factors on the variation of canopy size and structure of TRFSL along the above altitudinal gradient.

\section{METHODOLOGY}

\section{Study Sites, their Long-term Climate and Sampling Points}

Measurements of forest canopies were carried out using canopy hemispherical photography (CHP) in ten permanent sampling plots $(100 \mathrm{~m} \times 100 \mathrm{~m}=1$ ha) located along an altitudinal gradient from 117 $\mathrm{m}$ to $2132 \mathrm{~m}$ above mean sea level (amsl) (Figure 2). All sampling plots were located in forests in the climax or late-successional stage and were free from appreciable human influence and disturbance during the last 40 years. Long-term climatic variables of the study sites are given in Table 1.

\section{Canopy Hemispherical Photography: Image Acquisition and Processing}

Canopy size and structure were quantified by canopy hemispherical photography, which involves taking an upward-directed photograph of the canopy from the ground level using an extreme wide-angle fish-eye lens (Rich, 1990; Jonckheere et al., 2004).

The image provides the geometry of canopy gaps over the entire hemisphere covered by the forest canopy. Nine sampling points in a $25 \mathrm{~m} \times 25 \mathrm{~m}$ grid covering the entire 1 ha of each PSP were demarcated using PVC pipes for obtaining hemispherical photographs of the forest canopy. Images were taken with a self-levelling camera with the fish-eye lens fixed at a height of $1.3 \mathrm{~m}$ above the ground level during times of the day when the sky was either uniformly lit (i.e. clear skies) or uniformly overcast (i.e. uniformly cloudy). Focal length was adjusted to infinity and photographs were taken under auto exposure settings (Frazer et al., 1997). Image acquisition in all PSPs except PTD-1 and PTD-2 were done during the two-month period between January and February of 2020. Image acquisition in PTD-1 and PTD2 were done in July 2020.

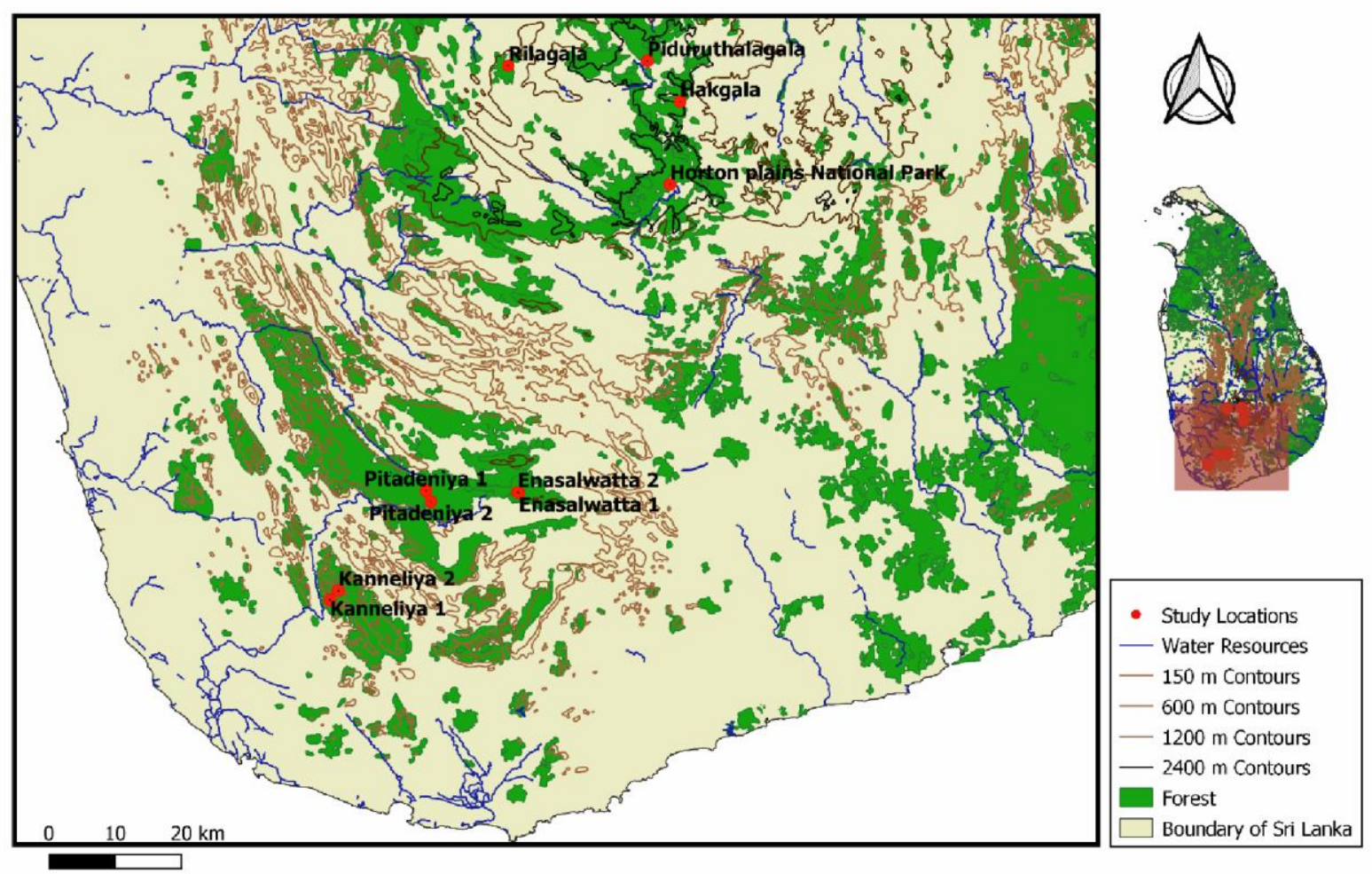

Figure 2: Locations of permanent sampling plots in tropical rainforests of Sri Lanka along an altitudinal gradient from $117 \mathrm{~m}$ to $2132 \mathrm{~m}$ above mean sea level. See Table 1 for further description of study sites and sampling plots. 
Table 1: Long-term (1970-2000) averages of climatic variables of $^{\prime}$ the study sites.

\begin{tabular}{|c|c|c|c|c|c|c|c|c|}
\hline PSP $^{\dagger}$ & $\begin{array}{l}\text { Alt } \\
\text { (m) }\end{array}$ & $\begin{array}{l}\mathrm{T}_{\mathrm{AV}} \\
\left({ }^{\circ} \mathrm{C}\right)\end{array}$ & $\begin{array}{c}\text { Tмaх }_{\text {мax }} \\
\left({ }^{\circ} \mathbf{C}\right)\end{array}$ & $\begin{array}{l}\text { TMIN }_{\text {MIN }} \\
\left({ }^{\circ} \mathrm{C}\right)\end{array}$ & $\begin{array}{c}\mathbf{R F}_{\mathbf{F}} \\
\left(\mathbf{m m} \mathbf{y}^{-1}\right)\end{array}$ & $\begin{array}{c}S_{R} \\
\left(M J ~ m^{-2} d^{-1}\right)\end{array}$ & $\begin{array}{c}V_{P} \\
(\mathrm{kPa})\end{array}$ & $\begin{array}{c}\text { WsP } \\
\left(\mathrm{m} \mathrm{s}^{-1}\right)\end{array}$ \\
\hline KDN-1 & 117 & 26.3 & 29.8 & 23.5 & 3656 & 18.945 & 2.8 & 2.3 \\
\hline $\mathrm{KDN}-2$ & 174 & 26.3 & 29.3 & 22.8 & 3788 & 18.833 & 2.8 & 2.3 \\
\hline PTD-1 & 509 & 23.7 & 26.9 & 20.4 & 3901 & 18.330 & 2.0 & 1.9 \\
\hline PTD-2 & 618 & 24.3 & 27.9 & 21.1 & 3877 & 18.496 & 2.2 & 1.9 \\
\hline ENS-1 & 1042 & 21.3 & 24.5 & 18.1 & 3103 & 17.910 & 2.0 & 2.2 \\
\hline ENS-2 & 1065 & 21.3 & 24.5 & 18.1 & 3103 & 17.910 & 2.0 & 2.2 \\
\hline RLG & 1668 & 18.6 & 22.1 & 14.9 & 2569 & 17.731 & 1.8 & 1.8 \\
\hline HKG & 1804 & 17.2 & 20.3 & 13.8 & 2017 & 17.688 & 1.8 & 2.0 \\
\hline PTG & 2080 & 15.3 & 18.4 & 12.3 & 1903 & 17.460 & 1.2 & 1.9 \\
\hline HNP & 2132 & 14.3 & 17.4 & 11.4 & 2038 & 17.398 & 1.2 & 2.1 \\
\hline
\end{tabular}

†PSP - Permanent Sampling Plots; KDN-1, KDN-2 - Kanneliya Forest Reserve Plot 1 and 2;

PTD-1, PTD-2 - Sinharaja-Pitadeniya Plot 1 and Plot 2; ENS-1, ENS-2 - Sinharaja Enasalwatte Plot 1 and Plot 2; RLG Rilagala Forest Reserve; HKG - Hakgala Strict Nature Reserve; PTG - Pidurutalagala Forest Reserve; HNP - Horton Plains National Park. Alt - Altitude; $\mathrm{T}_{\mathrm{AV}}, \mathrm{T}_{\mathrm{MAX}}$ and $\mathrm{T}_{\mathrm{MIN}}$ - Long-term averages of the mean, maximum and minimum temperatures; $\mathrm{R}_{\mathrm{F}}$ - Average annual precipitation; $\mathrm{S}_{\mathrm{R}}$ - Daily solar irradiance; $\mathrm{V}_{\mathrm{P}}$ - Mean vapour pressure; $\mathrm{W}_{\mathrm{SP}}-\mathrm{Mean}$ wind speed. \#Source: Fick and Hijmans (2017).

Images were processed using HemiView Canopy Analysis Software (Version 2.1, Delta-T Devices, Cambridge, UK). Non-canopy material (i.e. stems and branches) were deleted from the image using an RGB value of 255:0:1 in Adobe Photoshop (Version 11.0). After aligning the edited image with the magnetic north, lens properties were set as following prior to image processing: Lens - sigma EX DC $4.5 \mathrm{~mm}$; Lens description - Sigma EX DC fisheye on Canon EOS 80D camera; Field of view $180^{\circ}$; Lens coefficients: $A_{1} 0.706900, A_{2}-0.032900$, $\mathrm{A}_{3} 0.025600$ and $\mathrm{A}_{4}$ 0.021097. The solar model was set as following: Transmissivity - 0.55; Diffuse proportion - 0.1; External solar flux - $2900 \mu \mathrm{mol} \mathrm{m}{ }^{-}$ ${ }^{2} \mathrm{~S}^{-1}$; Diffuse distribution- uniform overcast sky (Anonymous, 1999).

HemiView considers the darker parts of the edited image as canopy elements and the whiter parts as the sky and provides a threshold toolbar to differentiate them. The optimum threshold value was selected manually to separate visible sky pixels (i.e. canopy gaps) from obstructed pixels (i.e. foliage elements). Each hemispherical image was analysed repeatedly until three precise results were obtained.

\section{Calculation of Canopy Properties}

Canopy leaf area index (LAI) was calculated by HemiView via an iterative algorithm which applies the Beer-Lambert Law of radiation penetration (Equation 1) to the gap fraction of the image.

$$
\mathrm{G}(\theta)=\mathrm{e}^{-\mathrm{k}(\theta) \mathrm{LAI}}
$$

(Equation 1)

where $G(\theta)$ and $k(\theta)$ are respectively the gap fraction and light extinction coefficient at a given solar zenith angle $(\theta)$. The gap fraction at different zenith angles in combination with the solar track at the location and time of image acquisition estimated the distribution of leaf area in the canopy assuming an ellipsoidal leaf angle distribution (Figure 1). In the iteration procedure to calculate LAI, HemiView initially calculates initial values of LAI and ELADP for a theoretical canopy with an ellipsoidal distribution of leaf elements that gives the best fits to the measured gap fraction of the hemispherical image. These initial best fit values of LAI and ELADP are used in the subsequent iterations until they converge on a minimum error sum of squares. The mean leaf angle (MLA), defined as the average angle of canopy leaf elements to the horizontal, for an ellipsoidally-distributed canopy is calculated by HemiView using the following integral, 


$$
M L A(x)=\frac{\int_{0}^{\frac{x}{2}} \sqrt{\sin (\alpha)^{2}+x^{2} \cdot \cos (\alpha)^{2}} \cdot a \tan \frac{\tan (\alpha)}{x} \cdot \sin (\alpha) \cdot d \alpha}{\int_{0}^{\frac{x}{2}} \sqrt{\sin (\alpha)^{2}+x^{2} \cdot \cos (\alpha)^{2}} \cdot \sin (\alpha) \cdot d \alpha}
$$

(Equation 2)

where, $\mathrm{x}$ is ELADP and $\alpha$ is the solar inclination angle (Figure 1) (Campbell, 1990; Anonymous, 1999).

\section{Data Analysis}

All statistical analyses were carried out with SAS Studio University Edition (SAS Institute Inc.). Significance of the variation of LAI, ELADP and MLA among tropical rainforests at different altitudes was tested by analysis of variance (ANOVA). Prior to ANOVA, normality of the pooled data sets was tested by the Shapiro-Wilks test statistic $(W)$ in Proc Univariate of SAS. When the data set deviated from the normal distribution, it was transformed into normality by an optimum power transformation using the 'Box-Cox' family of power transformations (Box and Cox, 1964). Response patterns of canopy properties to altitude and longterm climatic variables were determined by fitting second-order polynomial or linear functions. Multiple regression analysis was used to determine the best-fitting models to predict canopy structural properties from long-term climatic data. In determining the best-fitting model, multicollinearity among the independent variables was avoided by retaining variables with a variance inflation parameter of less than 10.

\section{RESULTS AND DISCUSSION}

\section{Canopy Leaf Area Index (LAI): Variation with Altitude and Long-Term Climate}

Pooling of computed LAI values from all sampling locations and PSPs showed that their overall distribution deviated from normality (ShapiroWilks $W=0.940, p=0.0004, \mathrm{n}=90$ ), being skewed to the right with a mean of 2.564 and median of 2.451 (Figure 3a). Box-Cox transformation of the original LAI data showed the optimal power transformation to be inverse square $\operatorname{root}(\lambda=-0.5)$. Application of this transformation achieved normality in the distribution of LAI data (ShapiroWilks $W=0.993, p=0.926$ ) (transformed data not shown). Analysis of variance of the transformed LAI showed highly-significant $(p<0.0001)$ variation in mean LAI of the forest canopy among PSPs (Figure 3b). Notably, LAI did not vary significantly $(p>0.05)$ among the nine sampling points within each PSP. The highest mean LAI of
3.38 was shown in Sinharaja-Pitadeniya Plot 2 (PTD-2) while the lowest (1.64) was in Pidurutalagala (PTG). These values were within the global-scale range of LAI values for tropical broadleaf evergreen vegetation as initially reported by Asner et al. (2003) (i.e. $1.5-8.0)$ and subsequently by Iio et al. (2014) (0.69 - 22.4). However, the overall mean LAI across the 10 PSPs of the present study (2.56) was lower than the respective mean values of 4.8 and 3.48 in Asner et al. (2003) and lio et al. (2014).

The mean LAI showed a significant $(p=0.032)$ second-order polynomial response to altitude (Figure 4). Accordingly, LAI of the forest canopy increased from lower altitudes (i.e. Kanneliya) up to the lower-mid altitude at Sinharaja-Pitadeniya and declined subsequently with increasing altitude. The canopy LAI was estimated to peak at $658 \mathrm{~m}$ amsl. A similar pattern of variation was reported by McJannet et al. (2007) for TRFs in Australia across an altitudinal gradient from $20 \mathrm{~m}$ to $1560 \mathrm{~m}$ amsl, where LAI peaked at $1100 \mathrm{~m}$ and declined beyond.

The mean LAI showed second-order polynomial relationships with long-term averages (Fick and Hijmans, 2017) of mean air temperature, $\mathrm{T}_{\mathrm{AV}}(p=$ $\left.0.061 ; R^{2}=0.551\right)$, maximum air temperature, $\mathrm{T}_{\mathrm{MAX}}$ $\left(p=0.062 ; R^{2}=0.548\right)$, minimum air temperature, $\mathrm{T}_{\mathrm{MIN}}\left(p=0.050 ; R^{2}=0.574\right)$, and daily solar irradiance ( $p=0.017 ; R^{2}=0.687$ ) (Figures $5 \mathrm{a}-\mathrm{d}$ ). Further, the mean LAI had a significant positive linear relationship with long-term average annual total precipitation ( $p=0.006 ; R^{2}=0.629$ ) (Figure $5 \mathrm{e})$. Second-order polynomial relationships between LAI and temperature, which are similar to the pattern observed in the present study have been observed by Battaglia et al. (1998), Luo et al. (2004) and Iio et al. (2014). There is a substantial body of literature, especially on agricultural crops, which shows that the rates of several key physiological processes responsible for determination of LAI (i.e. rates of leaf initiation, leaf expansion and assimilate supply for leaf 


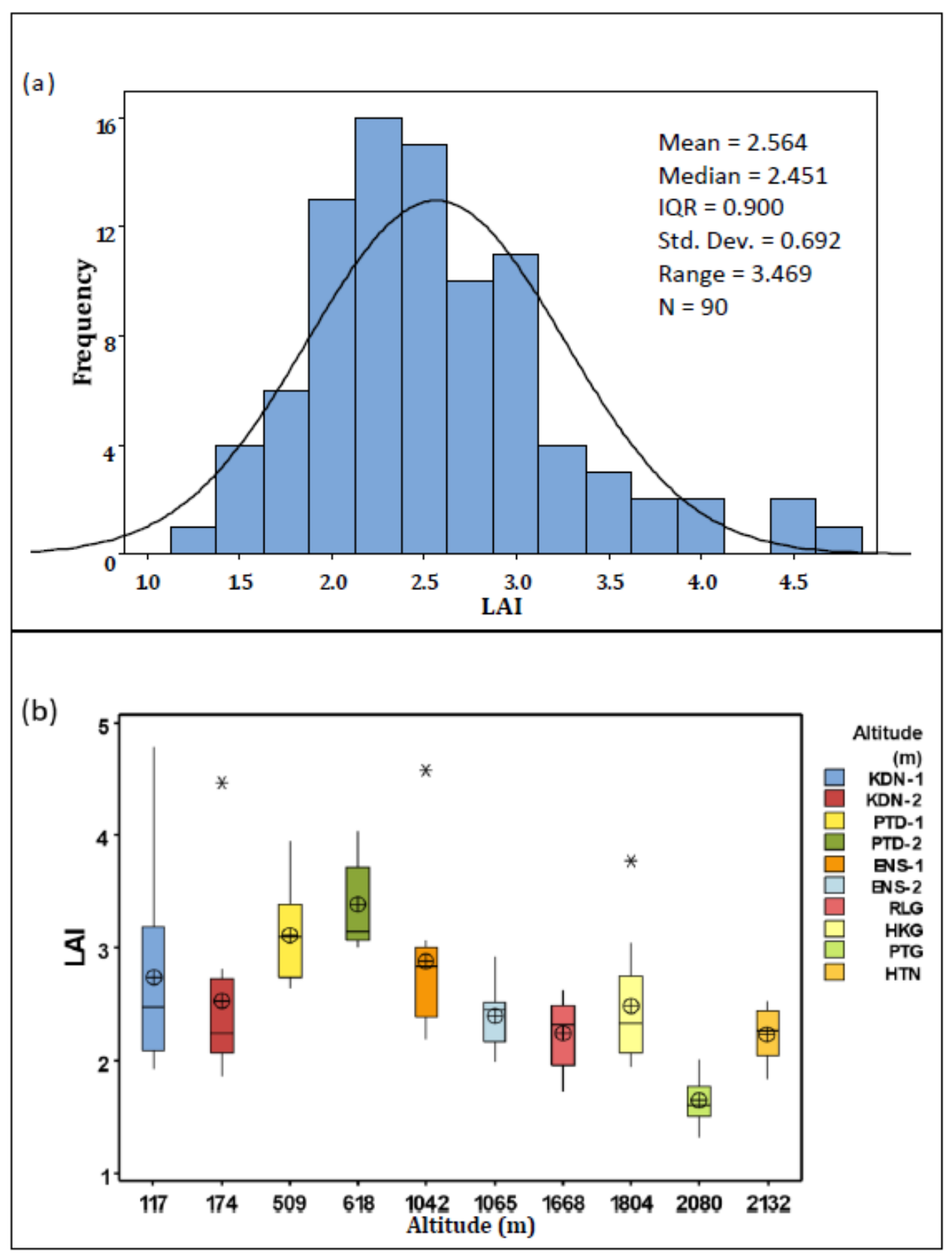

Figure 3: Distribution of canopy leaf index of tropical rainforests across an altitudinal gradient in Sri Lanka. (a) Frequency distribution with the normal curve overlain after pooling values from all sampling points and locations; (b) Box plots of distributions at different locations. In each box plot, the mean LAI is indicated by the circle.

Note: KDN-1, KDN-2 - Kanneliya Forest Reserve Plot 1 and 2; PTD-1, PTD-2 - Sinharaja-Pitadeniya Plot 1 and Plot 2; ENS-1, ENS-2 - Sinharaja-Enasalwatte Plot 1 and Plot 2; RLG - Rilagala Forest Reserve; HKG - Hakgala Strict Nature Reserve; PTG - Pidurutalagala Forest Reserve; HNP - Horton Plains National Park

grown) respond to temperature according to the second-order polynomial function (Squire, 1990; De Costa, 2004). Positive linear relationships between LAI and water availability have been reported by Grier and Running, (1977), Ellis and Hatton (2008), Schleppi et al. (2011) and Iio et al. (2014). This is because water availability is a key determinant of leaf expansion and their retention (Squire, 1990; De Costa, 2004).

The second-order polynomial relationship between LAI and $S_{R}$ indicates that the environmental control of LAI is determined by the balance between the two competing processes, carbon assimilation and transpiration, 


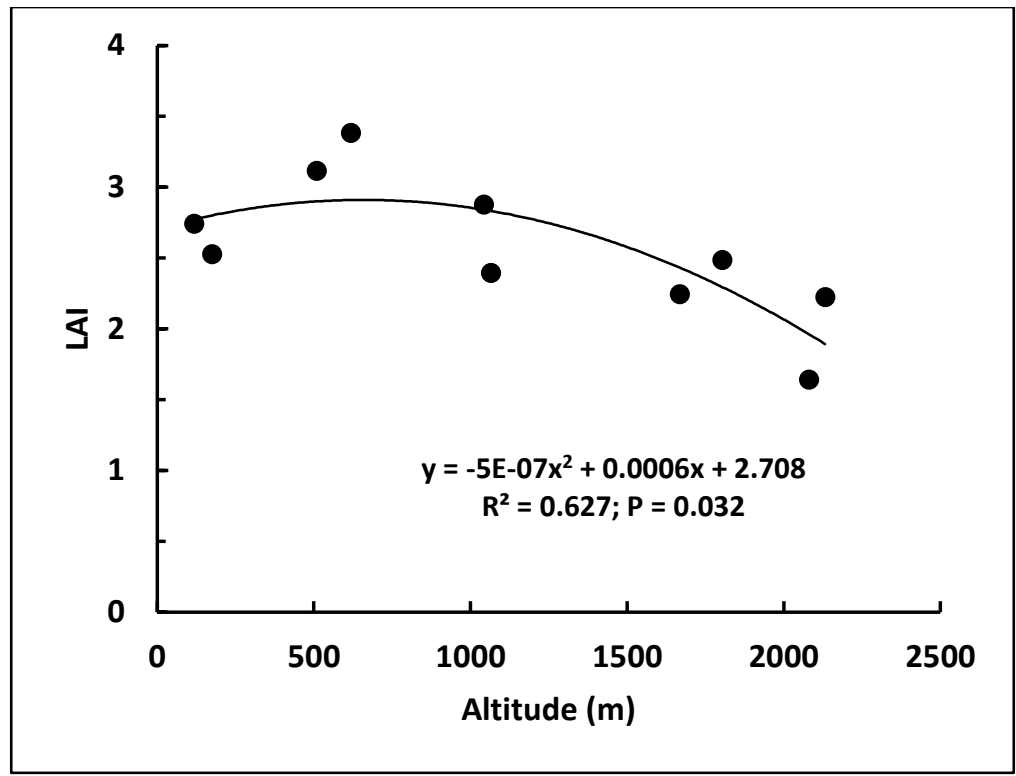

Figure 4: Response of the mean canopy leaf area index (LAI) of tropical rainforests in Sri Lanka to altitude

both of which are influenced by $S_{R}$ (Monteith and Unsworth, 1990; Squire, 1990; De Costa, 2004; Niinemets, 2010). Expansion of the foliage canopy is dependent on the allocation of new biomass to leaf growth. Accordingly, LAI increases with increasing $S_{R}$ as increased assimilation allocates a greater amount of assimilates to leaf growth. However, increasing LAI with increasing $S_{R}$ needs to be regulated as higher $\mathrm{LAI}$ at higher $\mathrm{S}_{\mathrm{R}}$ increases

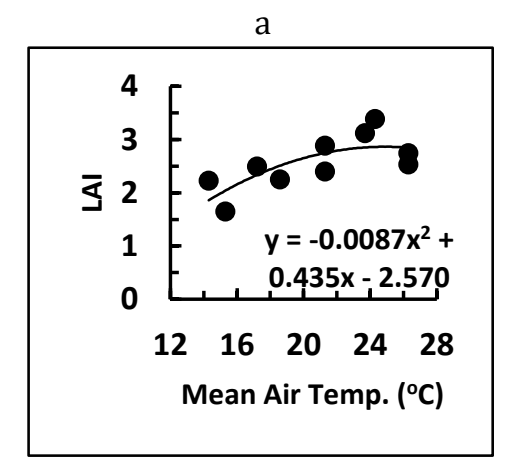

d

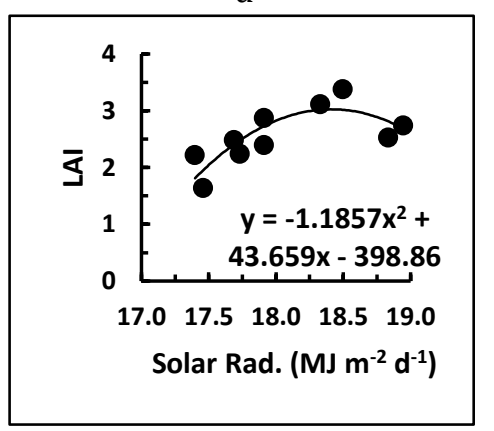

water loss via transpiration. Consequently, LAI could decrease with increasing $S_{R}$ beyond an optimum $S_{R}\left(18.41 \mathrm{MJ} \mathrm{m}^{-2} \mathrm{~d}^{-1}\right.$ in the present study, Figure 5d) to prevent excessive water loss. Evidence for this type of dynamic regulation of canopy LAI is provided by the 'Concept of Ecohydrological Equilibrium' as shown by Yang et al. (2018). $\mathrm{b}$

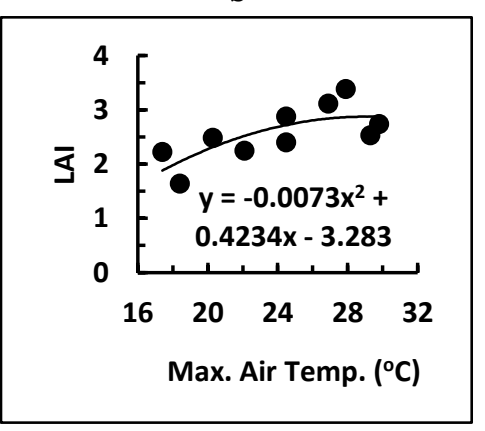

e

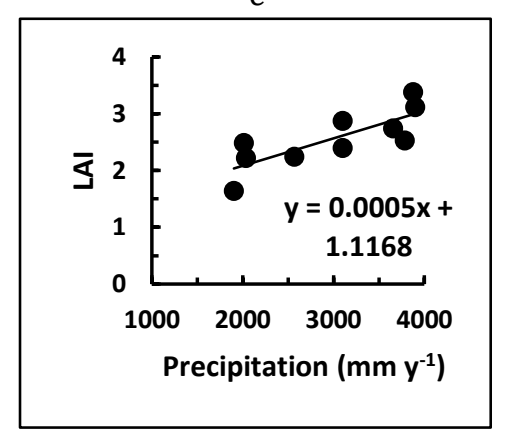

C

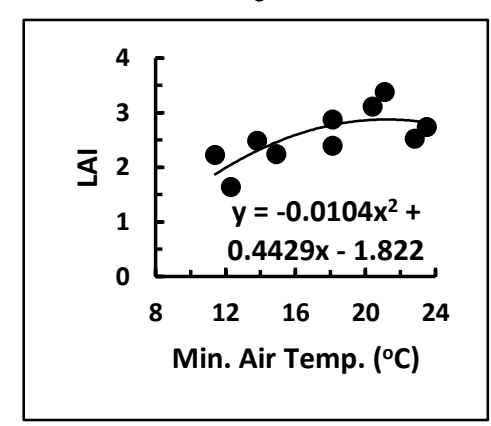

Figure 5: Responses of the mean canopy leaf area index of tropical rainforests in Sri Lanka to longterm averages of selected climatic variables: (a) Mean air temperature; (b) Maximum air temperature; (c) Minimum air temperature; (d) Mean daily solar irradiance; (e) Annual total precipitation. 
Table 2: Parameter estimates of the best-fitting multiple regression models to predict mean LAI of tropical rainforests along an altitudinal gradient in Sri Lanka

\begin{tabular}{|c|c|c|c|c|c|}
\hline \multicolumn{3}{|c|}{ Model 1} & \multicolumn{3}{|c|}{ Model 2} \\
\hline Variable & $\begin{array}{c}\text { Parameter } \\
\text { estimate }\end{array}$ & $\begin{array}{c}\text { Standardized } \\
\text { estimate }\end{array}$ & Variable & $\begin{array}{c}\text { Parameter } \\
\text { estimate }\end{array}$ & $\begin{array}{c}\text { Standardized } \\
\text { estimate }\end{array}$ \\
\hline Intercept & 1.53675 & 0 & Intercept & 7.162 & 0 \\
\hline $\mathrm{R}_{\mathrm{F}}$ & 0.00088091 & 1.445 & $\mathrm{R}_{\mathrm{F}}$ & 0.000708 & 1.162 \\
\hline $\mathrm{T}_{\mathrm{AV}}$ & -0.07731 & -0.683 & $S_{R}$ & -0.372 & -0.414 \\
\hline$p$ & 0.021 & & $p$ & 0.022 & \\
\hline$R^{2}$ & 0.670 & & $R^{2}$ & 0.664 & \\
\hline
\end{tabular}

Multiple regression, after removing multicollinearity, identified two models which had equal $R^{2}$, to predict mean LAI from climatic variables. One model included mean annual air temperature $\left(\mathrm{T}_{\mathrm{AV}}\right)$ and annual total precipitation $\left(R_{F}\right)$ while the other included $R_{F}$ and daily solar irradiance $\left(S_{R}\right)$ (Table 2). In the first model, $T_{A V}$ had a negative effect on LAI whereas $R_{F}$ had a positive effect. In the second model also $\mathrm{R}_{\mathrm{F}}$ had a positive relationship with mean LAI, but $S_{R}$ had a negative relationship. Comparison of the standardized parameter estimates of both models showed that the positive influence of $R_{F}$ was greater than the negative influences of $\mathrm{T}_{\mathrm{AV}}$ and $\mathrm{S}_{\mathrm{R}}$. The stronger influence of $R_{F}$ over $T_{A V}$ is in agreement with the global scale analysis of Iio et al. (2014). The influence of $\mathrm{R}_{\mathrm{F}}$ on LAI would be stronger at relatively lower $\mathrm{R}_{\mathrm{F}}$ (Donohue et al., 2009; Donohue et al., 2013; Jin and Goulden, 2014), as for example, at higher altitude locations of this study (i.e. Sinharaja-Enasalwatte, Rilagala, Hakgala, Pidurutalagala and Horton Plains). The interrelationships among the three long-term climatic variables (Figure 6) show that at the higher-end of the $\mathrm{R}_{\mathrm{F}}$ range, both $\mathrm{T}_{\mathrm{AV}}$ (Figure $6 \mathrm{a}$ ) and $\mathrm{S}_{\mathrm{R}}$ (Figure $6 \mathrm{~b}$ ) decreased with increasing $\mathrm{R}_{\mathrm{F}}$. This variation in climate occurred from Kanneliya (altitude 117 m $174 \mathrm{~m}$ amsl) to Sinharaja-Pitadeniya (altitude 509 $\mathrm{m}-618 \mathrm{~m}$ ) where the mean LAI increased with altitude (Figure 4).

Therefore, at the higher $\mathrm{R}_{\mathrm{F}}$ range, where the influence of $\mathrm{R}_{\mathrm{F}}$ would be lower, the mean LAI has increased with decreasing $\mathrm{T}_{A V}$ and $\mathrm{S}_{\mathrm{R}}$. This has been shown in the multiple regression models as the negative effects of $\mathrm{T}_{\mathrm{AV}}$ and $\mathrm{S}_{\mathrm{R}}$ on LAI, when the effect $R_{F}$ is removed.

\section{Ellipsoidal Leaf Angle Distribution Parameter (ELADP): Variation with Altitude and Long-Term Climate}

Distribution of pooled ELADP values from all sampling points and PSPs was highly skewed to the right (Figure 7a) and deviated significantly from normality (Shapiro-Wilks $W=0.940, p=0.0004, \mathrm{n}$ =90). Forest canopies at a large majority of sampling points had ELADP values greater than one along with both the mean (2.226) and the median (1.639). This indicated forest canopies in which a majority of leaves were relatively
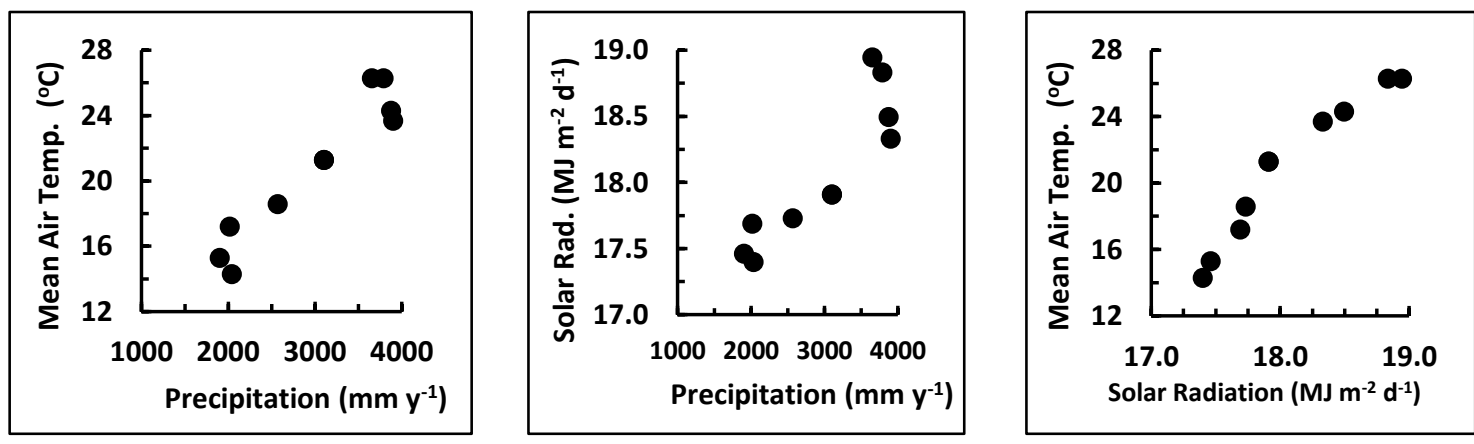

Figure 6: Co-variation of long-term averages of selected climatic variables in permanent sampling plots of tropical rainforests in Sri Lanka along an altitudinal gradient. 


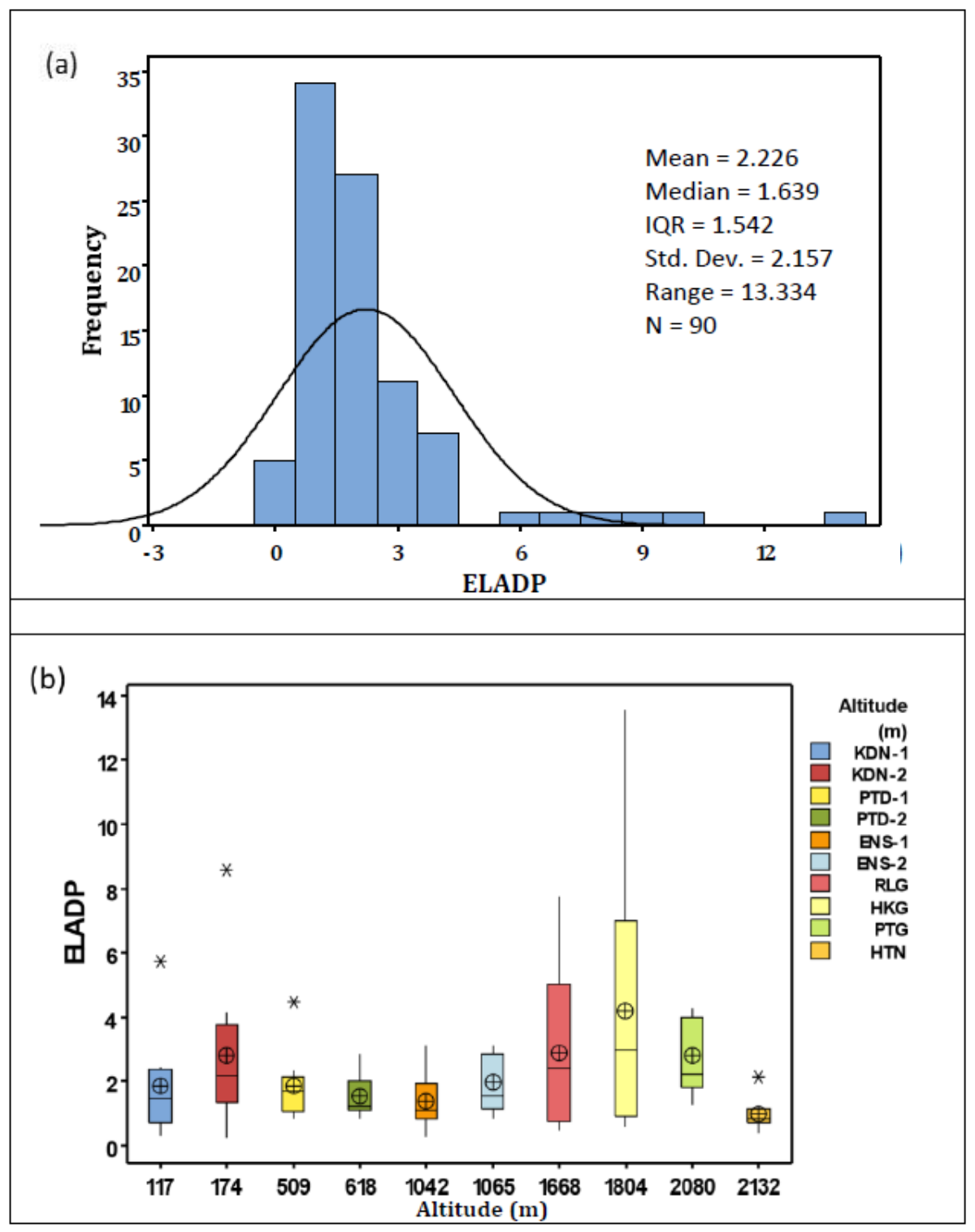

Figure 7: Distribution of canopy leaf angle distribution parameter of tropical rainforests across an altitudinal gradient in Sri Lanka: (a) Frequency distribution with the normal curve overlain after pooling values from all sampling points and locations; (b) Box plots of distributions at different locations. In each box plot, the mean ELADP is indicated by the circle.

Note: KDN-1, KDN-2 - Kanneliya Forest Reserve Plot 1 and 2; PTD-1, PTD-2 - Sinharaja-Pitadeniya Plot 1 and Plot 2; ENS-1, ENS-2 - Sinharaja-Enasalwatte Plot 1 and Plot 2; RLG - Rilagala Forest Reserve; HKG - Hakgala Strict Nature Reserve; PTG - Pidurutalagala Forest Reserve; HNP - Horton Plains National Park.

horizontally-oriented with a minority of verticallyoriented leaves. Box-Cox data transformation identified the natural $\log$ transformation $(\lambda=0)$ as the optimum and the transformed data showed normality (Shapiro-Wilks $W=0.988, p=0.613$ ). Analysis of variance of transformed ELADP showed significant $(p=0.084)$ variation in mean ELADP among PSPs (Figure 7b).

Forest canopies at different sampling points within a PSP did not differ significantly $(p>0.05)$ in their ELADP. The mean ELADP at the plot level ranged from 0.977 at Horton Plains to 4.188 at Hakgala. All PSPs except at Horton Plains had mean ELADPs greater than one, thus confirming the predominance of relatively horizontally-oriented leaves in a majority of forest canopies. This variation of forest canopy architiecture at different locations and altitudes could be due to several factors. The diversity of tree species occupying different strata of the canopy in TRFs (Gunatilleke and Gunatilleke, 1985) could determine the leaf angle distribution of the entire canopy as different species could inherently have different leaf angles. 
For example, Wirth et al. (2001) showed that leaf angle decreased exponentially from the canopy top to the bottom in a mature TRF. Furthermore, leaf clumping and layering within and among different species in a TRF could influence the ELADP (Niinemets, 2010). Variation of canopy height and depth could also influence the leaf angle distribution by determining the number of vertical strata in the forest canopy (Ashton et al., 2001; Giuliani and Brown, 2008; Whitehurst et al., 2013). These aspects will be quantified in a future work on the PSPs of the present study.

Mean ELADP did not show any clear trend with altitude or any of the climatic variables. However, when the data point at Horton Plains is excluded, mean ELADP showed a second-order polynomial response ( $\left.p=0.124 ; R^{2}=0.502\right)$ to increasing altitude (Figure 8). Here, mean ELADP showed a slight decreasing trend from lower altitudes until reaching a minimum at $716 \mathrm{~m}$ amsl, which was followed by an increasing trend up to $2080 \mathrm{~m}$ amsl at Pidurutalagala. This pattern is an inversion of the corresponding pattern shown by the mean LAI (Figure 4). Accordingly, LAI and ELADP were negatively-correlated at the plot mean $(r=-0.556$; $p=0.120 ; \mathrm{n}=9)$ and individual sampling point $(r=$ -0.366; $p=0.0004 ; \mathrm{n}=90$ ) levels. This meant that as the LAI increased from the lower- (Kanneliya) to lower mid- (Sinharaja-Pitadeniya) altitudes, leaf angle distribution shifted towards increasing the proportion of relatively vertically-oriented leaves. Further, the more horizontally-oriented leaves became more abundant in the forest canopies as their LAI decreased from lower mid- to mid- and upper altitudes (Sinharaja-Enasalwatte).

When the data point at Horton Plains is excluded, mean ELADP showed linear declining trends with $\mathrm{T}_{\mathrm{AV}}\left(p=0.114 ; R^{2}=0.318\right), \mathrm{T}_{\mathrm{MAX}}\left(p=0.101 ; R^{2}=\right.$ $0.338), \mathrm{T}_{\mathrm{MIN}}\left(p=0.099 ; R^{2}=0.339\right)$ and $\mathrm{R}_{\mathrm{F}}(p=$ $0.124 ; R^{2}=0.502$ ) (Figures $9 \mathrm{a}-\mathrm{c}, \mathrm{e}$ ) and a secondorder polynomial trend with $\mathrm{S}_{\mathrm{R}}\left(p=0.280 ; R^{2}=\right.$ 0.346) (Figure 9d). These linear and nonlinear trends of ELADP with climatic variables could be a consequence of the regulation of LAI by the climatic variables (as shown earlier) and the negative correlation between LAI and ELADP. As LAI decreased with decreasing $S_{R}$ (Figure $5 d$ ) at higher altitudes (Figure 6), the increasing proportion of more horizontally-oriented leaves could be an adaptation to maximize radiation interception in this tropical latitude where solar radiation is incident from a high zenith angle for most of the day. A similar adjustment in the leaf angle distribution has occurred with increasing $S_{R}$ from lower-mid to lower altitudes (Figure 9d). As explained earlier, LAI decreased with increasing $S_{R}$ to regulate transpiration at the higher end of the $S_{R}$ (and $\mathrm{T}_{\mathrm{AV}}$ ), thus causing the leaf angle distribution to shift towards a higher proportion of horizontal leaves in this altitudinal range. Similarly, ELADP has increased with decreasing precipitation (Figure 9e) in response to the reduction of LAI (Figure 5e).

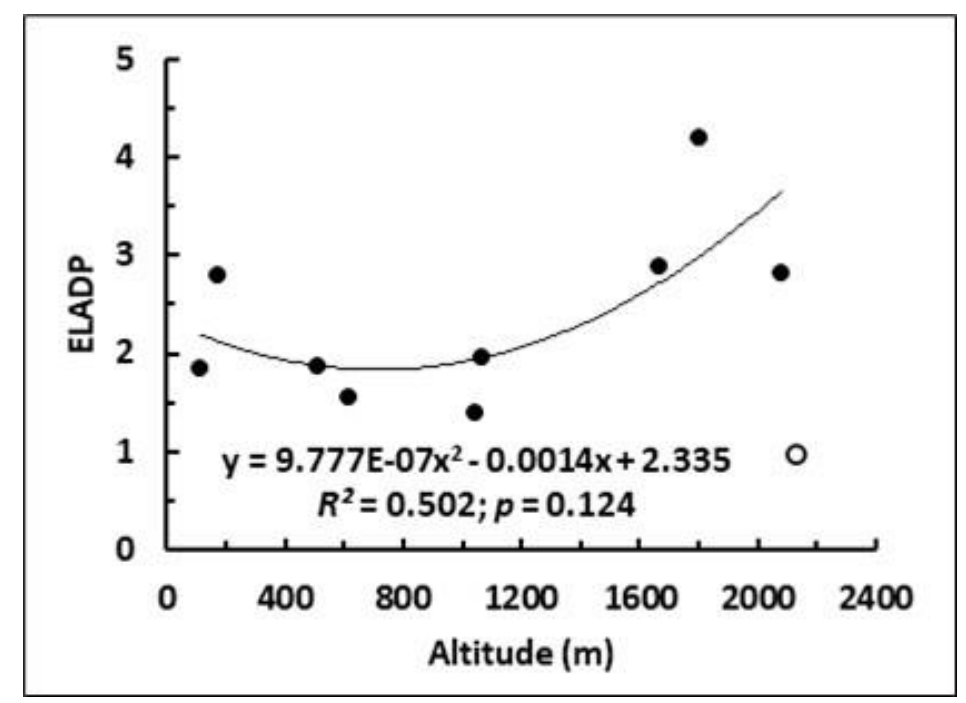

Figure 8: Response of the canopy ellipsoidal leaf angle distribution parameter (ELADP) of tropical rainforests in Sri Lanka to altitude. The curve has been fitted to the data set (closed circles) excluding the data point at Horton Plains (shown by the open circle). 
a

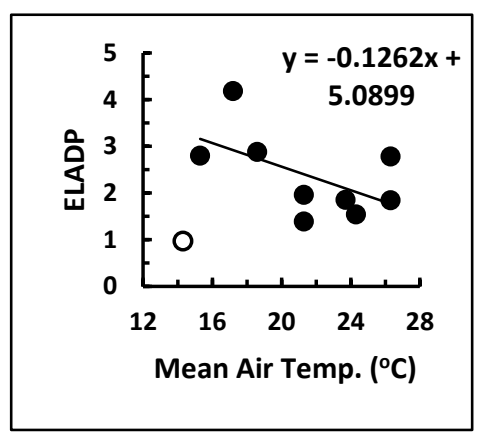

d

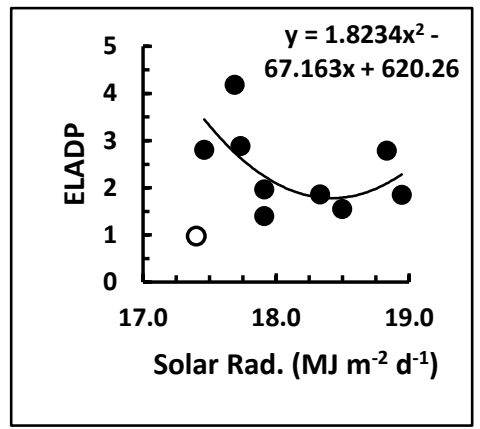

b

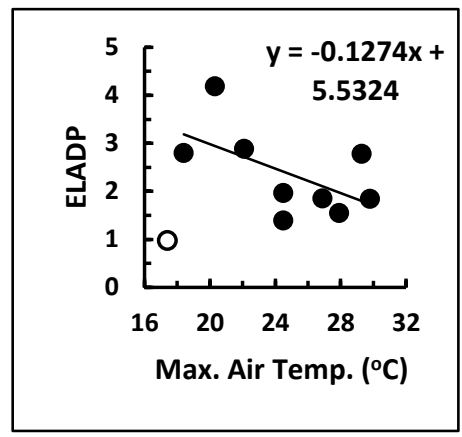

$\mathrm{e}$

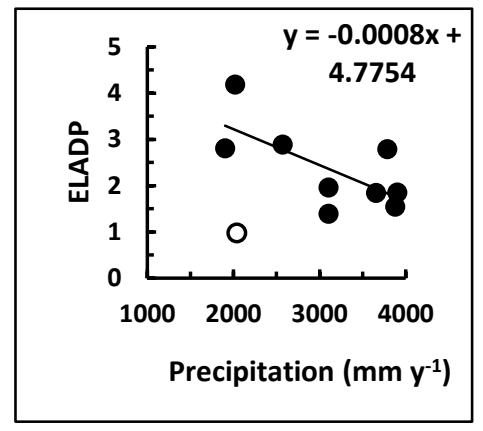

C

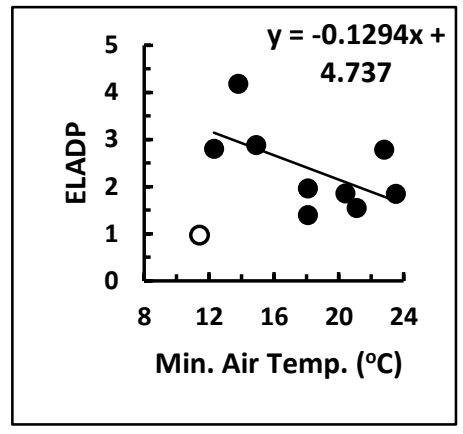

Figure 9: Responses of the mean canopy leaf angle distribution parameter of tropical rainforests in Sri Lanka to long-term averages of selected climatic variables. (a) Mean air temperature; (b) Maximum air temperature; (c) Minimum air temperature; (d) Mean daily solar irradiance; (e) Annual total precipitation. Curves have been fitted to the data set (closed circles) excluding the data point at Horton Plains (shown by the open circle).

\section{Mean leaf angle (MLA): Variation with Altitude and Long-Term Climate}

Pooled data of MLA from all sampling points and PSPs were normally-distributed (Shapiro-Wilks $W$ $=0.988, p=0.610, \mathrm{n}=90$ ) (Figure 10a). Analysis of variance showed that mean MLA varied significantly ( $p=0.064)$ among different PSPs, but did not show significant variation among different sampling points. Mean MLA was highest at Horton Plains $\left(58.5^{\circ}\right)$ and lowest at Pidurutalagala $\left(32.3^{\circ}\right.$ ) (Figure 10b).

The mean_MLA did not show clear trends with altitude or climatic variables. However, when the data point at Horton Plains was excluded, mean MLA showed second-order polynomial relationships with altitude (Figure 11), $\mathrm{T}_{\mathrm{AV}}(p=$ $\left.0.048 ; R^{2}=0.636\right), \mathrm{T}_{\mathrm{MAX}}\left(p=0.057 ; R^{2}=0.615\right), \mathrm{T}_{\mathrm{MIN}}$ $\left(p=0.062 ; R^{2}=0.605\right), \mathrm{S}_{\mathrm{R}}\left(p=0.062 ; R^{2}=0.605\right)$ and $\mathrm{R}_{\mathrm{F}}\left(p=0.043 ; R^{2}=0.650\right)$ (Figures $\left.12 \mathrm{a}-\mathrm{e}\right)$. The maximum MLA was observed at an altitude of 773 $\mathrm{m}$ amsl, which was close to the altitude of $716 \mathrm{~m}$ at which ELADP reached its minimum. As the proportion of relatively horizontally oriented leaves increased with increasing altitude above $716 \mathrm{~m}$ the MLA decreased with increasing altitude above $773 \mathrm{~m}$. The respective optima for $\mathrm{T}_{\mathrm{AV}}, \mathrm{T}_{\mathrm{MAX}}$, $\mathrm{T}_{\mathrm{MIN}}, \mathrm{S}_{\mathrm{R}}$ and $\mathrm{R}_{\mathrm{F}}$ were $23.0{ }^{\circ} \mathrm{C}, 26.5^{\circ} \mathrm{C}, 20.0^{\circ} \mathrm{C}, 18.41$ MJ $\mathrm{m}^{-2}$ day $^{-1}$ and $3296 \mathrm{~mm}^{-1}$ year ${ }^{-1}$. As explained earlier with respect to LAI and ELADP, the reduction of MLA from mid to higher altitudes was an adaptation to maximize radiation interception as $S_{R}$ decreased with increasing altitude. Further, the reduction of MLA with decreasing altitude from mid to lower altitudes was an adaptation to maximize radiation interception as LAI decreased to control transpiration.

The best-fitting multiple regression models, after removing multicollinearity, to predict mean ELADP and MLA included $R_{F}$ and $S_{R}$ (Table 3). The $R_{F}$ exerted a negative effect on ELADP and a positive effect on MLA. Moreover, $S_{R}$ had a positive effect on ELADP and a negative effect on MLA. On both these parameters of canopy architecture, the influence of $\mathrm{R}_{\mathrm{F}}$ was greater than that of $\mathrm{S}_{\mathrm{R}}$. 


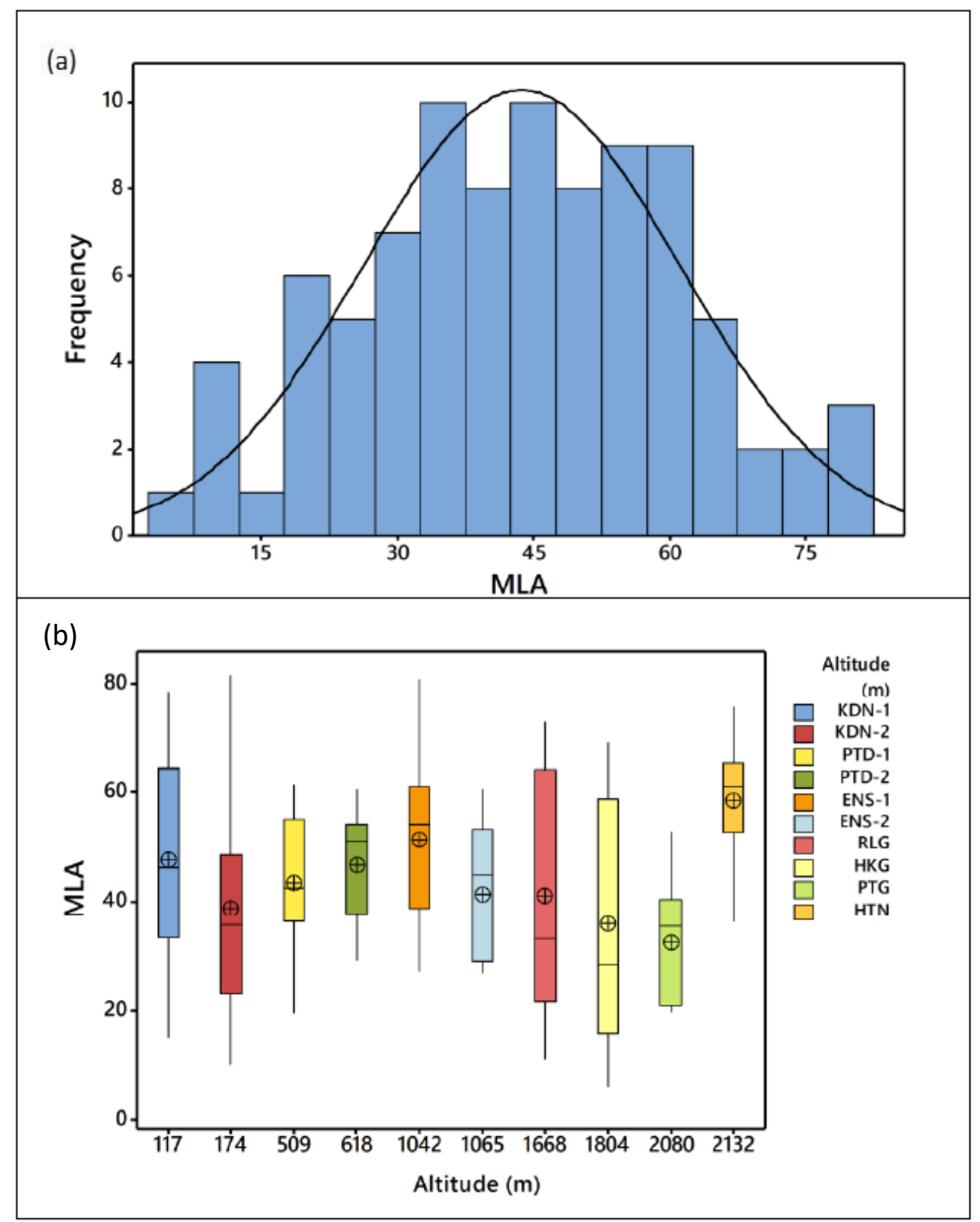

Figure 10: Distribution of mean leaf angle of the canopies of tropical rainforests across an altitudinal gradient in Sri Lanka: (a) Frequency distribution with the normal curve overlain after pooling values from all sampling points and locations; (b) Box plots of distributions at different locations. In each box plot, mean MLA is indicated by the circle.

As shown earlier, ELADP was negativelycorrelated to LAI whereas MLA was positively correlated to LAI at the plot mean $(r=0.758$; $p=$ $0.018 ; \mathrm{n}=9)$ and individual sampling point $(r=$ $0.558 ; p<0.0001 ; \mathrm{n}=90)$. Therefore, the effects of $\mathrm{R}_{\mathrm{F}}$ and $\mathrm{S}_{\mathrm{R}}$ in best-fitting multiple regression models to predict ELADP and mean MLA could be explained in terms of the above correlations with LAI and how $\mathrm{R}_{\mathrm{F}}$ and $\mathrm{S}_{\mathrm{R}}$ determined LAI (explained earlier).
It is notable that the two parameters describing the architecture of the forest canopy at Horton Plains were outliers to the overall pattern shown by forest canopies of the rest of the plots despite its LAI fitting-in with the overall patterns. The specific reason/s for this are not clear within the present study and need further investigation. At the global scale across wide latitudinal and longitudinal ranges, Iio et al. (2014) observed an inverse S shaped curve for the variation of LAI with mean annual temperature with two peaks at $8.9^{\circ}$ and $25.0^{\circ} \mathrm{C}$. 


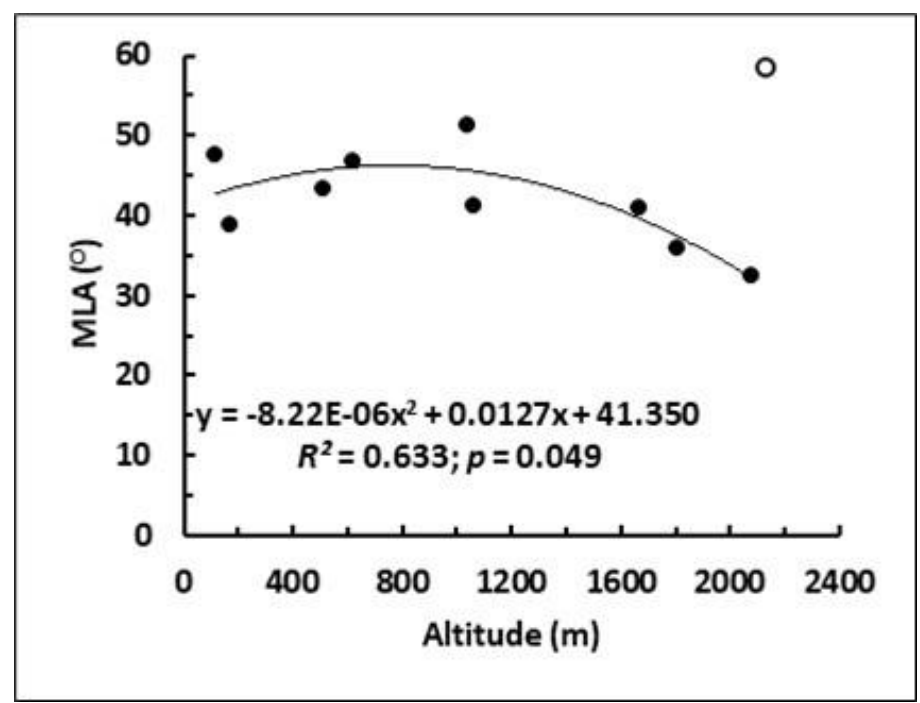

Figure 11: Response of the mean leaf angle (MLA) of the canopies of tropical rainforests in Sri Lanka to altitude. The curve has been fitted to the data set (closed circles) excluding the data point at Horton Plains (shown by the open circle).

a

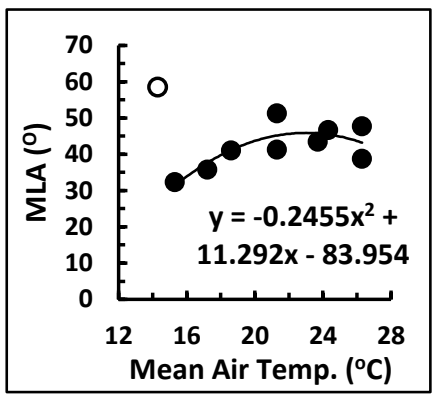

d

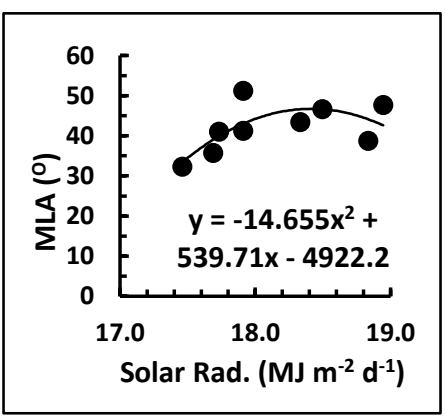

b

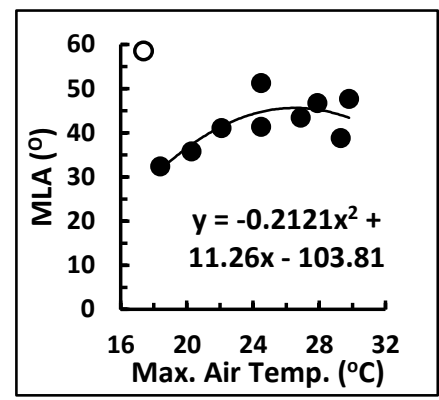

e

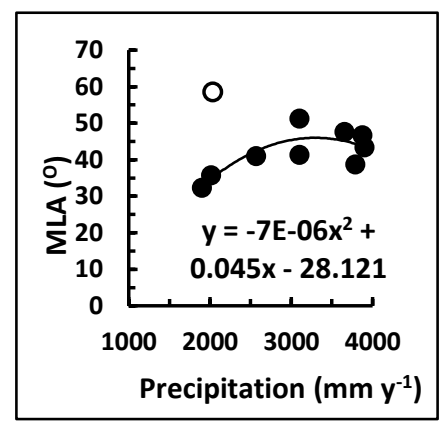

C

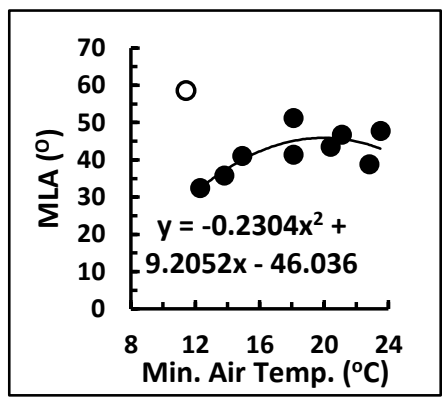

Figure 12: Responses of mean canopy leaf angle of tropical rainforests in Sri Lanka to long-term averages of selected climatic variables. (a) Mean air temperature; (b) Maximum air temperature; (c) Minimum air temperature; (d) Mean daily solar irradiance; (e) Annual total precipitation. Curves have been fitted to the data set (closed circles) excluding the data point at Horton Plains (shown by the open circle). 
Table 3: Parameter estimates of the best-fitting multiple regression models to predict canopy architecture of tropical rainforests along an altitudinal gradient in Sri Lanka

\begin{tabular}{lcccc}
\hline \multirow{2}{*}{ Variable } & \multicolumn{2}{c}{ Ellipsoidal Leaf Angle Distribution Mean Leaf Angle Parameter } \\
\cline { 2 - 5 } & $\begin{array}{c}\text { Parameter } \\
\text { estimate }\end{array}$ & $\begin{array}{c}\text { Standardized } \\
\text { estimate }\end{array}$ & $\begin{array}{c}\text { Parameter } \\
\text { estimate }\end{array}$ & $\begin{array}{c}\text { Standardized } \\
\text { estimate }\end{array}$ \\
\hline Intercept & -15.892 & 0 & 94.145 & 0 \\
$\mathrm{R}_{\mathrm{F}}$ & -0.00152 & -1.34427 & 0.00741 & 0.973 \\
$\mathrm{~S}_{\mathrm{R}}$ & 1.265 & 0.75562 & -4.141 & -0.366 \\
$p$ & 0.057 & & 0.155 & \\
$R^{2}$ & 0.616 & & 0.463 & \\
\hline
\end{tabular}

As both ELADP and MLA were correlated to LAI, their outlier at Horton Plains could be an indication of the inverse S-shaped curve observed by lio et al. (2014) for LAI. However, this needs further investigation for confirmation.

\section{CONCLUSION}

Based on the findings of this work, it is concluded that both canopy size (LAI) and canopy architecture (quantified in terms of ELADP and MLA) of TRFSL vary with altitude in response to the variation of climate associated with it. The long-term mean annual precipitation exerts the strongest effect on LAI of TRFSL, which is positive and linear. In the high precipitation environments ( $>3000 \mathrm{~mm}$ year $^{-1}$ ), solar irradiance and temperature exerts negative effects on LAI. These responses demonstrate that water availability is

\section{REFERENCES}

Anonymous. (1999). HemiView User Manual (Version Version 2.1). Delta-T Devices, Cambridge, UK.

Ashton, M.S., Gunatilleke, C.V.S., Singhakumara, B.M.P. and Gunatilleke, I.A.U.N. (2001). Restoration pathways for rain forest in southwest Sri Lanka: a review of concepts and models. Forest Ecology and Management. 154, 409-430.

Asner, G.P., Scurlock, J.M.O. and Hicke, J. A. (2003). Global synthesis of leaf area index observations: implications for ecological and remote sensing studies. Global Ecology and Biogeography . 12, 191-205.

Battaglia, M., Cherry, M.L., Beadle, C.L., Sands, P.J. and Hingston, A. (1998). Prediction of leaf area index in eucalypt plantations: effects of water the key determinant of LAI in TRFSL. Responses of canopy architectural properties are correlated to the variations of LAI and solar irradiance. When LAI decreases in response to decreasing precipitation or increasing irradiance under high precipitation, in order to maximize radiation interception, canopy architecture moves towards having a greater proportion of leaves with relatively horizontal-orientation and a lower mean canopy leaf angle.

\section{ACKNOWLEDGEMENTS}

This work was funded by the National Science Foundation, Sri Lanka (Grant NTRP/ 2017/ CC\&ND/ TA-04/ P-01/ 01). Assistance in field work from Dineth Dhanushka and Suneth Kanishka is acknowledged.

stress and temperature. Tree Physiology. 18, 521-528.

Box, G.E.P. and Cox, D.R. (1964). An analysis of transformations. Journal of the Royal Statistical Society 26, 211-243.

Campbell, G.S. (1986). Extinction coefficients for radiation in plant canopies calculated using an ellipsoidal inclination angle distribution. Agricultural and Forest Meteorology. 36, 317321.

Campbell, G.S. (1990). Derivation of an angle density function for canopies with ellipsoidal leaf angle distributions. Agricultural and Forest Meteorology. 49, 173-176.

Chianucci, F. and Cutini, A. (2012). Digital hemispherical photography for estimating forest canopy properties: current controversies 
and opportunities. iForest - Biogeosciences and Forestry, 5, 290-295.

De Costa, W.A.J.M. (2004). Principles of Crop Physiology. University of Peradeniya, Peradeniya.

Donohue, R.J., McVicar, T.R. and Roderick, M.L. (2009). Climate-related trends in Australian vegetation cover as inferred from satellite observations, 1981--2006. Global Change Biology. 15, 1025-1039.

Donohue, R.J., Roderick, M.L., McVicar, T.R. and Farquhar, G.D. (2013). Impact of $\mathrm{CO}_{2}$ fertilization on maximum foliage cover across the globe's warm, arid environments.

Geophysical Research Letters. 40, 3031-3035.

Ediriweera, S., Singhakumara, B.M.P. and Ashton, M.S. (2008). Variation in canopy structure, light and soil nutrition across elevation of a Sri Lankan tropical rain forest.

Forest Ecology and Management. 256, 1339-1349.

Ellis, T.W. and Hatton, T.J. (2008). Relating leaf area index of natural eucalypt vegetation to climate variables in southern Australia. Agricultural Water Management. 95, 743-747.

Fick, S.E. and Hijmans, R.J. (2017). WorldClim 2: new $1-\mathrm{km}$ spatial resolution climate surfaces for global land areas. Int. J. Climatology. 37, 4302-4315.

Fotis, A.T. and Curtis, P.S. (2017). Effects of structural complexity on within-canopy light environments and leaf traits in a northern mixed deciduous forest. Tree Physiology. 37, 1426-1435.

Fournier, R.A. and Hall, R.J. (2017). Hemispherical Photography in Forest Science: Theory, Methods, Applications. Springer, Dordrecht.

Frazer, G.W., Trofymow, J.A. and Lertzman, K.P. (1997). A method for estimating canopy openness, effective leaf area index, and photosynthetically active photon flux density using hemispherical photography and computerized image analysis techniques. Information Report BC-X-373, Canadian Forest Service/Forest Ecosystem Process Network. Pacific Forestry Centre, Victoria, B.C.

Giuliani, R. and Brown, K.J. (2008). Within-canopy sampling of global irradiance to describe downwelling light distribution and infer canopy stratification in a broadleaf forest. Tree Physiology. 28, 1407-1419.

Grier, C.G. and Running, S.W. (1977). Leaf Area of Mature Northwestern Coniferous Forests: Relation to Site Water Balance. Ecology, 58, 893-899.

Gunatilleke, C.V.S. and Ashton, P.S. (1987). New Light on the Plant Geography of Ceylon. II. The Ecological Biogeography of the Lowland Endemic Tree Flora. Journal of Biogeography. $14,295-327$.

Gunatilleke, C.V.S. and Gunatilleke, I.A.U.N. (1985). Phytosociology of Sinharaja-A contribution to rain forest conservation in Sri Lanka. Biological Conservation, 31, 21-40.

Gunatilleke, I.A.U.N. and Gunatilleke, C.V.S. (1984). Distribution of endemics in the tree flora of a lowland hill forest in Sri Lanka. Biological Conserveation. 28, 275-285.

Iio, A., Hikosaka, K., Anten, N.P.R., Nakagawa, Y. and Ito, A. (2014). Global dependence of fieldobserved leaf area index in woody species on climate: a systematic review. Global Ecology and Biogeography. 23, 274-285.

Jin, Y. and Goulden, M.L. (2014). Ecological consequences of variation in precipitation: separating short-versus long-term effects using satellite data. Global Ecology and Biogeography .. 23, 358-370.

Jonckheere, I., Fleck, S., Nackaerts, K., Muys, B., Coppin, P., Weiss, M. and Baret, F. (2004). Review of methods for in situ leaf area index determination: Part I. Theories, sensors and hemispherical photography. Agricultural and Forest Meteorology. 121, 19-35.

Körner, C. (2007). The use of "altitude" in ecological research. Trends in Ecology \& Evolution 22, 569-574.

Luo, T., Pan, Y., Ouyang, H., Shi, P., Luo, J., Yu, Z. and Lu, Q. (2004). Leaf area index and net primary productivity along subtropical to alpine gradients in the Tibetan Plateau. Global Ecology and Biogeography. 13, 345-358.

McJannet, D., Wallace, J. and Reddell, P. (2007). Precipitation interception in Australian tropical rainforests: II. Altitudinal gradients of cloud interception, stemflow, throughfall and 
interception. Hydrological Processes. 21, 17031718.

Monteith, J.L. and Unsworth, M.H. (1990). Principles of Environmental Physics - Second Edition. Edward Arnold.

Niinemets, Ü. (2010). A review of light interception in plant stands from leaf to canopy in different plant functional types and in species with varying shade tolerance. Ecological Research. $25,693-714$.

Pearcy, R.W. (2000). Radiation and light measurements. pp. 97-116. In: R.W. Pearcy, Ehleringer, J.R., Mooney, H.A. and Rundel, P.W. (Eds.) Plant Physiological Ecology: Field methods and instrumentation. Springer, Netherlands.

Perry, S.G., Fraser, A.B., Thomson, D.W. and Norman, J.M. (1988). Indirect sensing of plant canopy structure with simple radiation measurements. Agricultural and Forest Meteorology. 42, 255-278.

Rich, P.M. (1990). Characterizing plant canopies with hemispherical photographs. Remote Sensing Reviews. 5, 13-29.

Sanjeewani, H.K.N., Samarasinghe, D.P., Jayasinghe, H.D., Gardiyawasam, P.H., Wahala, W. M.P.S.B., Wijetunga, W.M.G.A.S.T.B., Ukuwela, K.D.B., Gomes, P. and De Costa, W.A.J.M. (2020). Response of tree community composition, plant diversity and aboveground tree biomass in tropical rainforests of Sri Lanka to variation in altitude. Tropical Agricultural Research, 31, 87101.
Schleppi, P., Thimonier, A. and Walthert, L. (2011). Estimating leaf area index of mature temperate forests using regressions on site and vegetation data.Forest Ecology and Management. 261, 601-610.

Squire, G.R. (1990). The Physiology of Tropical Crop Production. C.A.B. International, Wallingford.

Wang, W.-M., Li, Z.-L. and Su, H.-B. (2007). Comparison of leaf angle distribution functions: Effects on extinction coefficient and fraction of sunlit foliage. Agricultural and Forest Meteorology. 143, 106-122.

Welles, J.M. and Norman, J.M. (1991). Instrument for indirect measurement of canopy architecture. Agronomy Journal. 83, 818-825.

Whitehurst, A.S., Swatantran, A., Blair, J.B., Hofton, M.A. and Dubayah, R. (2013). Characterization of canopy layering in forested ecosystems using full waveform Lidar. Remote Sensing. 5, 20142036.

Wirth, R., Weber, B. and Ryel, R.J. (2001). Spatial and temporal variability of canopy structure in a tropical moist forest. Acta Oecological. 22, 235-244.

Yang, J., Medlyn, B.E., De Kauwe, M.G. and Duursma, R.A. (2018). Applying the concept of ecohydrological equilibrium to predict steady state leaf area index. Journal of Advances in Modeling Earth Systems. 10, 1740-1758. 